\title{
Synthesis of geopolymer spheres with photocatalytic activity
}

\author{
Patricia Isabel Bravo ${ }^{1}$, Roy Alvin Malenab ${ }^{2}$, Eiza Shimizu ${ }^{1}$, Derrick Ethelbhert $\mathrm{Yu}^{1}$, and Michael Angelo Promentilla ${ }^{2, *}$ \\ ${ }^{1}$ Department of Chemistry, College of Science, De La Salle University, 2401 Taft Avenue, Manila 1004, Philippines \\ ${ }^{2}$ Department of Chemical Engineering, Gokongwei College of Engineering, De La Salle University, 2401 Taft Avenue, \\ Manila 1004, Philippines
}

\begin{abstract}
Geopolymer is an emerging "green" cementitious material which has a potential to valorize waste such as rice hull ash (RHA). Geopolymer is a kind of alkali-activated material which forms from the reaction of alumino-silicates in an alkaline solution. This study uses RHA as the raw material for alkaline activator while metakaolin (MK) serves as a geopolymer precursor to synthesize the so-called geopolymer sphere. Then its capacity as a porous matrix was explored upon incorporation of $\mathrm{TiO} 2$ nanomaterial using horizontal vapor phase growth (HVPG) technique to enhance its photocatalytic property. Indication suggests that the synthesized MK-geopolymer spheres activated with RHA-based water glass solution (WGS) were comparable to that of commercial WGS. Furthermore, the geopolymer spheres were successfully coated with $\mathrm{TiO} 2$ in the form of nanocrystals. Its photocatalytic activity was evaluated in terms of methylene blue degradation. This material's potential environmental application for water purification and wastewater treatment will be investigated for future works.
\end{abstract}

\section{Introduction}

The Philippines is an agricultural country whose staple is rice, generating around 19 million metric tons (MMT) of paddy rice in 2017 alone. This has increased by around $8 \%$ from the previous year [1]. This implies that rice hull, its agricultural residue, is also produced in large quantities and is steadily increasing thereby posing an environmental threat through its disposal [2]. With the existing problem of rice hull generation that far outweighs its utilization, several strategies to make use of this waste have emerged, one of which is in concrete production [3]. The cement industry is responsible for approximately $2.4 \%$ of $\mathrm{CO}_{2}$ emission, this in due of it being a by-product of its calcination process and from the combustion of fossil fuels such as coal to provide large amount of energy needed to manufacture ordinary Portland cement (OPC) [4]. Because of its low energy consumption during its processing, researchers have now shifted their focus on the use of waste materials or its by-products (pozzolanic materials) as ingredients in concrete production with the objective of having minimal environmental impact and maximal sustainability [5].

Fortunately, a new innovation in the concrete industry has emerged that is versatile enough to be produced from waste materials. This new innovation is termed as geopolymers. Geopolymers are inorganic polymers having a long-range covalent framework. It is a product of the alkaline activation of alumino-silicate materials having tetrahedral units of varying $\mathrm{Al} / \mathrm{Si}$ ratio $[2,6]$. Recently, this material has been gaining popularity because of its potential to replace OPC. Aside from the fact that it is a more sustainable option given that it can be produced from industrial wastes, its processing requires less energy, thereby reducing $\mathrm{CO}_{2}$ emission relative to OPC. Furthermore, its mechanical properties are also comparable to that of OPC [2]. Rice hull ash (RHA), a combustion product of rice hull, contains a good source of amorphous silica that is about $85-90 \%$ [2,7], an integral component in geopolymers. In order to provide a solution to make use of its mass production and disposal problems, this study opted a utilization strategy by making use of rice hull ash, along with metakaolin (MK) which contains around $52 \% \mathrm{SiO}_{2}[5,8]$, as key ingredients in geopolymer.

With the dual objective of reducing carbon footprint and degrading pollutants, geopolymers were shown to be a promising catalyst support matrix of photoactive compounds for two reasons: (a) Geopolymers are resistant to acid attacks that are products of degraded pollutants [9]; (b) Geopolymers are thermally stable that can withstand up to $1300^{\circ} \mathrm{C}$, a feature that allows it to be coated with nano-sized particles for an improved photocatalytic performance $[6,10]$.

Photocatalysts have been used in concrete materials with self-cleaning surfaces for the degradation of water and air pollutants. The most widely used photoactive compound is titanium dioxide or titania $\left(\mathrm{TiO}_{2}\right)$, due to its excellent optical and chemical stability, low cost, nontoxicity and efficiency. Its photocatalytic process occurs through absorption of $\mathrm{UV}$ radiation, then, adsorbed $\mathrm{O}_{2}$ and $\mathrm{H}_{2} \mathrm{O}$ molecules on the $\mathrm{TiO}_{2}$ surface are converted into reactive oxygen species (ROS), which then react and

\footnotetext{
Corresponding author: michael.promentilla@dlsu.edu.ph
} 
degrade the pollutants. It is incorporated into the concrete material through (1) direct addition to the cement powder or (2) dissolution in water followed by its addition to cement [11]. However, since the photocatalytic ability of $\mathrm{TiO}_{2}$ occurs on the surface, $\mathrm{TiO}_{2}$ particles incorporated inside the concrete material is a waste. Thus, in order to explore a more suitable, if not better, incorporation method, $\mathrm{TiO}_{2}$ is deposited on the geopolymer sphere surface using Horizontal Vapor Growth Deposition (HVPG) technique [12] to fully maximize its photocatalytic activity and produce an efficient photocatalyst.

This study was done in order to: (1) Address the disposal problems and mass production of waste material and pozzolanic materials that are abundant in the Philippines. This was done by the utilization of such materials in making the geopolymer spheres: metakaolin (MK) as the mineral mixture and rice hull ash (RHA) for preparing an alkaline activator.; (2) Enhance the application of the geopolymer sphere by using it as a catalyst support matrix of photoactive compounds. This was done upon coating with $\mathrm{TiO}_{2}$; (3) Explore a more suitable $\mathrm{TiO}_{2}$ coating method using Horizontal Vapor Phase Growth (HVPG) that may allow an enhanced photocatalytic performance. These were assessed using techniques such as scanning electron microscopy (SEM) and energy dispersive x-ray (EDX). Photocatalytic performance was then evaluated upon degradation of methylene blue (MB).

\section{Materials and methods}

\subsection{Materials}

Metakaolin and rice hull ash were used and received from a materials recovery facility in Tarlac province. Chemical composition of these materials using X-ray fluorescence (XRF) analysis are summarized in Table 1.

Table 1. Composition of metakaolin and rice hull ash

\begin{tabular}{|c|c|c|}
\hline Oxides & Metakaolin & $\begin{array}{c}\text { Rice hull } \\
\text { ash }\end{array}$ \\
\hline $\mathrm{SiO}_{2}$ & 54.5 & 72.2 \\
\hline $\mathrm{Al}_{2} \mathrm{O}_{3}$ & 43.7 & - \\
\hline $\mathrm{Fe}_{2} \mathrm{O}_{3}$ & 0.8 & 8.2 \\
\hline $\mathrm{K}_{2} \mathrm{O}$ & 0.5 & 8.5 \\
\hline $\mathrm{CaO}$ & 0.2 & 7.1 \\
\hline others & 0.4 & 4.0 \\
\hline LOI & 0.6 & 12.1 \\
\hline
\end{tabular}

Sodium hydroxide $(\mathrm{NaOH})$, commercial water glass solution (water glass solution modulus $=2.5 ; 34.1 \mathrm{wt} \%$ $\mathrm{SiO}_{2}, 14.7$ wt $\% \mathrm{Na}_{2} \mathrm{O}$ ), Polyethylne glycol with average molecular weight of $600 \mathrm{~g} / \mathrm{mol}$ (PEG-600), polysorbate 80 and titanium (IV) oxide anatase $(99.8 \%)$ were also used without further processing or purification.

\subsection{Experimental set-up}

The general flow of this study is illustrated in Figure 1. This study starts with the synthesis of water glass solution (WGS), which was used as an activator to form the geopolymer spheres. The spheres were then used as substrate by deposition of titania using HVPG technique.

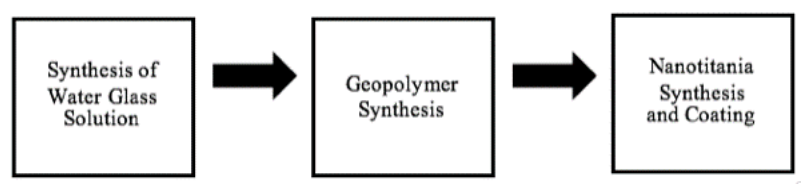

Figure 1. General flow of the experiment

\subsubsection{Synthesis of water glass solution}

Fig. 2 shows the schematic flow for the synthesis of geopolymer spheres.

Part I: Preparation of WGS or alkaline activator from rice hull ash. RHA and sodium hydroxide $(\mathrm{NaOH})$ solution were refluxed at $90^{\circ} \mathrm{C}$. Time, $\mathrm{NaOH}$ concentration and modulus $\left(\mathrm{m}_{\mathrm{SiO} 2} / \mathrm{m}_{\mathrm{Na} 2 \mathrm{O}}\right)$ were varied to determine the optimal parameter (Table 2). Then, the solution was filtered and stored at room temperature.

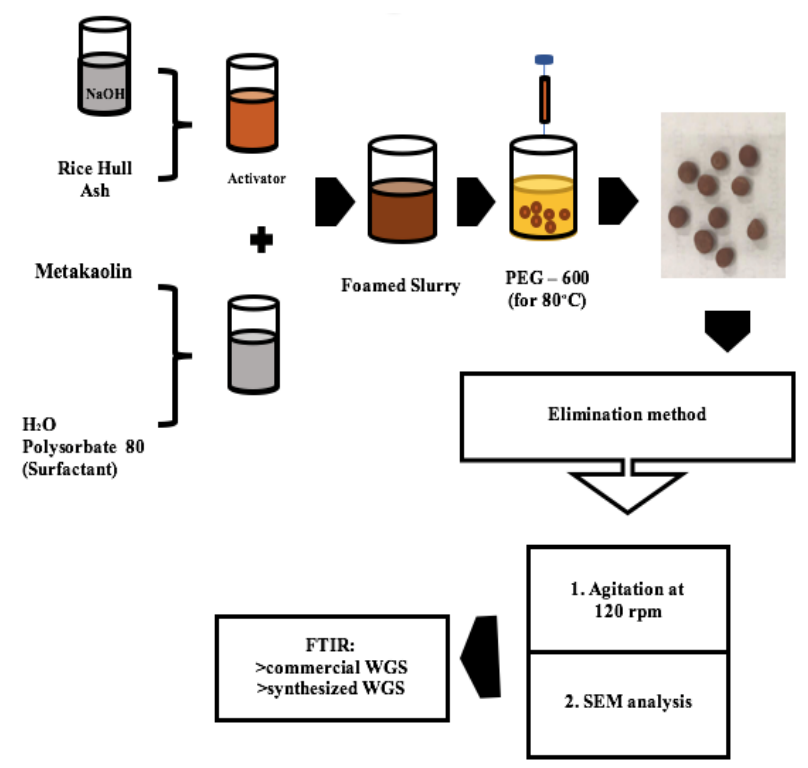

Figure 2. Schematic flow of the synthesis of geopolymer spheres.

Table 2. Varying parameters and range used for the method optimization of the synthesis of water glass solution from rice hull ash

\begin{tabular}{|c|c|}
\hline Parameter & Range \\
\hline Time, $(h)$ & 2,4 \\
\hline $\mathrm{NaOH}$ Concentration, $\mathrm{C}\left(\mathrm{mol} \mathrm{L}^{-1}\right)$ & $7.5,12$ \\
\hline $\mathrm{m}_{\mathrm{SiO} 2} / \mathrm{m}_{\mathrm{Na} 2 \mathrm{O}}$ & 2,3 \\
\hline
\end{tabular}

Part II: Preparation of the foamed slurry. Metakaolin was added to the optimized RHA-based WGS $\left(\mathrm{m}_{\mathrm{SiO} 2} / \mathrm{m}_{\mathrm{Na} 2 \mathrm{O}}=2\right)$, in $\mathrm{MK} /$ activator mass ratio $=2.5$. Then, $1.5 \%$ Polysorbate 80 , as the foaming agent, and water were added, and the mixture was stirred for 5 minutes to obtain the foamed slurry.

Part III: Formation of the porous geopolymeric spheres. The foamed slurry was placed in a $10 \mathrm{~mL}$ syringe 
and was dropped into $\mathrm{PEG}-600 \mathrm{kept}$ at $80^{\circ} \mathrm{C}$ temperature. PEG -600 is essential as its surfactant-like nature reduces the surface tension of the geopolymer beads to a minimum allowing it to have a spherical shape. The beads were left immersed in PEG-600 for about 20 minutes and was collected and washed by acetone. The beads were cured at room temperature for 24 hours followed by curing at $75^{\circ} \mathrm{C}$ for 2 days. The beads produced are around 2-3 $\mathrm{mm}$ in diameter.

\subsubsection{Nanotitania synthesis and coating}

Fig. 3 shows the set-up inside the quartz tube for the deposition of $\mathrm{TiO}_{2}$ onto the Geopolymer sphere. The beads were placed inside a closed-end quartz tube along with about $10 \mathrm{mg}$ of $\mathrm{TiO}_{2}$. The closed end quartz tube was then attached to the Thermoionics High Vacuum System and sealed under a vacuum pressure of $10^{-6}$ Torr. This was then placed inside a Thermolyne tube programmable furnace and was allowed to dwell at $1200^{\circ} \mathrm{C}$. In order to determine the time it takes for the deposition of $\mathrm{TiO}_{2}$ on its nano-sized form, the dwelling time was set to 2, 4 and 6 hours. The quartz tube was then fragmented after the dwelling process and the geopolymer sphere was then collected. The spheres were observed using SEM - EDX for its surface morphology and chemical composition.

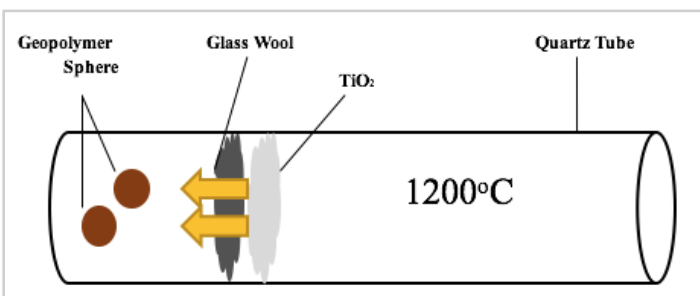

Figure 3. Set-up for the deposition of $\mathrm{TiO}_{2}$ on the Geopolymer Sphere

\subsubsection{Photocatalytic activity}

The photocatalytic activity of the $\mathrm{TiO}_{2}$-coated geopolymer spheres were evaluated in terms of methylene blue (MB) degradation. Four pieces of the coated beads were placed in methylene blue solution and was stirred for 30 minutes in the dark, to establish an absorption/desorption equilibrium. Then, the solution was exposed to UV light for 10 hours. The concentration of the final solution was determined by measuring its absorbance using UV-Vis spectrophotometer. The \% degradation was calculated as:

$$
\% \text { degradation }=\frac{/[\text { MBinit }]-[\text { MBfin }] /}{[\text { MBinit }]} \times 100 \%
$$

where

$\left[\mathrm{MB}_{\text {init }}\right]=$ initial $\mathrm{MB}$ concentration

$\left[\mathrm{MB}_{\text {fin }}\right]=\mathrm{MB}$ concentration after UV exposure

3 Results and discussion

\subsection{Stability of geopolymer beads activated by synthesized RHA-based water glass solution}

The water glass solution synthesized from rice hull ash was used solely for producing geopolymer spheres. Thus, the method for the synthesis of water glass solution using RHA as silica source was optimized by varying the parameters stated in Table 2. The raw material used as the alumino-silicate source was metakaolin was sourced from Tarlac, Philippines $\left(\mathrm{SiO}_{2}=55.06 \mathrm{wt} \%\right.$ and $\mathrm{Al}_{2} \mathrm{O}_{3}=$ $44.12 \%$ wt), which allows it to become a feasible geopolymer raw material.

Table 3. Summary of results for parameter optimization.

\begin{tabular}{|c|c|c|c|c|c|}
\hline $\mathrm{m}_{\mathrm{SiO} 2} / \mathrm{m}_{\mathrm{Na} 2 \mathrm{O}}$ & $\begin{array}{l}\mathrm{NaOH} \\
\text { Conc. } \\
\text { (mol } \\
\mathrm{L}^{-1} \text { ) }\end{array}$ & $\begin{array}{c}\text { Reflux } \\
\text { time } \\
\text { (h) }\end{array}$ & $\begin{array}{l}\text { Color } \\
\text { of the } \\
\text { solution }\end{array}$ & $\begin{array}{l}\text { With visible } \\
\text { macro-cracks } \\
\text { (after } \\
\text { agitation } \\
\text { at } 120 \mathrm{rpm} \text { ) }\end{array}$ & $\begin{array}{c}\text { With visible } \\
\text { micro-cracks } \\
\text { using SEM } \\
\text { analysis }\end{array}$ \\
\hline \multirow{2}{*}{2} & \multirow{2}{*}{$7.5 \mathrm{M}$} & 2 hrs & Yellow & I & ---- \\
\hline & & $4 \mathrm{hrs}$ & Orange & X & I \\
\hline \multirow{2}{*}{2} & \multirow{2}{*}{$12 \mathrm{M}$} & $2 \mathrm{hrs}$ & Yellow & X & I \\
\hline & & $4 \mathrm{hrs}$ & Orange & X & $X$ \\
\hline \multirow{2}{*}{3} & \multirow{2}{*}{$7.5 \mathrm{M}$} & $2 \mathrm{hrs}$ & Yellow & I & ---- \\
\hline & & $4 \mathrm{hrs}$ & Orange & $X$ & I \\
\hline \multirow{2}{*}{3} & \multirow{2}{*}{$12 \mathrm{M}$} & $2 \mathrm{hrs}$ & Yellow & X & I \\
\hline & & $4 \mathrm{hrs}$ & Orange & $X$ & X \\
\hline
\end{tabular}

The summary for the determination of the optimal parameter for the synthesized water glass solution (WGS) from rice hull ash is provided in Table 3. After agitation and SEM analysis of the geopolymer spheres, the following observations can be inferred from the water glass solutions:

1. Two hours reflux time was enough to produce spheres, after agitation, only when the $\mathrm{NaOH}$ concentration is $12 \mathrm{M}$.

2. Four hours reflux time was enough to produce stable spheres at $7.5 \mathrm{M} \mathrm{NaOH}$ and $12 \mathrm{M} \mathrm{NaOH}$ in both ratios after agitation.

3. Two-hour reflux time produces a solution that is yellow in color while four-hour reflux time produced solution that is orange in color. This is a result of the amount of elements extracted from the ash.

The optimal parameter was then selected using two consecutive elimination methods: (1) Elimination of experimental runs with observed macro-cracks using the naked eye after agitation at $120 \mathrm{rpm}$; (2) Macro-crack free spheres were then observed by SEM analysis to check for micro-cracks within the integrity of the selected spheres. If any sphere exhibited any cracking, the WGS by which it was formed was eliminated.

Figure 4 shows the scanning electron microscope (SEM) images of geopolymer spheres synthesized using $12 \mathrm{M} \mathrm{NaOH}$ and refluxed for 4 hour. It is evident that the geopolymer sphere exhibited a distinct porous structure and showed no signs of cracks on the surface as well as within its pores. Further, FTIR analyses revealed that the synthesized RHA-based water glass solution is comparable to commercial water glass solution (modulus $=2.5 ; \mathrm{SiO}_{2}=34.1 \mathrm{wt} \%, \mathrm{Na}_{2} \mathrm{O}=14.7 \mathrm{wt} \%$ ). Thus, from the results, it was found that the optimal parameter to 
produce stable geopolymer spheres is after the four-hour reflux time in $12 \mathrm{M} \mathrm{NaOH}$ for both mass ratios.

(a)
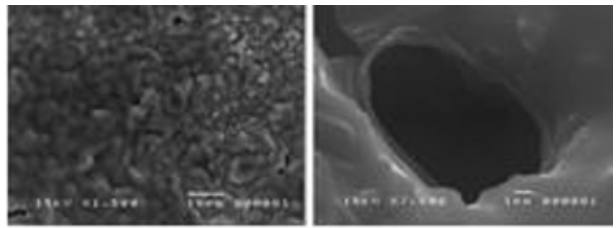

(b)

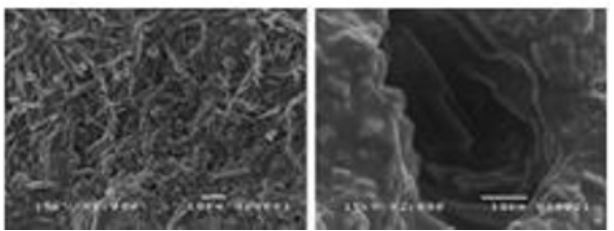

Figure 4. SEM analysis of the geopolymer spheres synthesized at 4 hours reflux time in $12 \mathrm{M} \mathrm{NaOH}$ using $\mathrm{m}_{\mathrm{SiO} 2} / \mathrm{m}_{\mathrm{NaOH}}$ equal to (a) 2 and (b) 3 mass ratio.

\section{2 $\mathrm{TiO}_{2}$ growth on geopolymer sphere surface by HVPG technique}

The set up inside the quartz tube is shown in Figure 3. In this set-up, at $1200^{\circ} \mathrm{C}$, sublimed $\mathrm{TiO}_{2}$ particles passes through the glass wool, which then travel towards the cooler part of the tube, and deposits on the geopolymer surface. Glass wool was placed in between the beads and $\mathrm{TiO}_{2}$ powder to ensure that the unreacted $\mathrm{TiO}_{2}$ powder is separated from the geopolymer sphere. The dwelling temperature was kept at $1200^{\circ} \mathrm{C}$ (maximum oven temperature), while the dwelling time was varied to determine the optimum conditions for the $\mathrm{TiO}_{2}$ deposition. Figure 5 shows the SEM images of the geopolymer spheres baked at 2, 4, and 6 hours. It can be clearly seen that at constant dwelling temperature of $1200^{\circ} \mathrm{C}$ and varying dwelling time, the deposited $\mathrm{TiO}_{2}$ particles on the geopolymer sphere had different morphologies. As the dwelling time is increased, $\mathrm{TiO}_{2}$ size and dimension consequently increased. Upon reaching the six-hour dwelling time, $\mathrm{TiO}_{2}$ morphology has stretched itself in the form of nanocrystals with an average width ranging from $180-250 \mathrm{~nm}$. Further, the nanocrystals seem to embed itself in the geopolymer sphere, providing larger $\mathrm{TiO}_{2}$ surface area which enhances its photocatalytic activity since this feature if highly dependent on the area of titania exposed. This is very beneficial as high crystallinity of anatase on its nanometer form improves its capacity to degrade pollutants $[12,13]$ and thus, improve the selfcleaning capacity of the cementitious material [15]. (a)

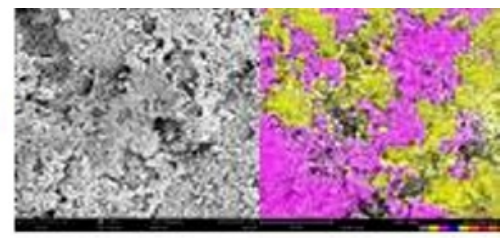

(b)

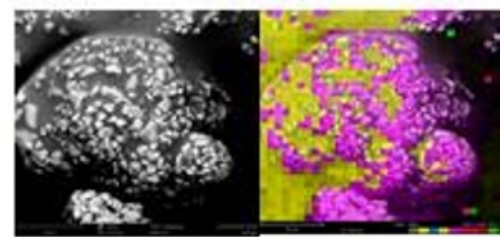

(c)

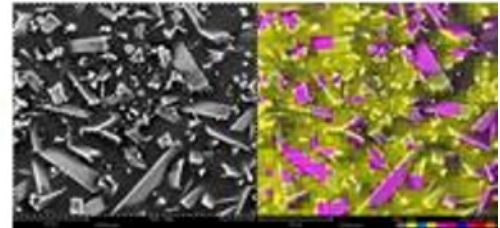

Figure 5. SEM images (left) and elemental map (right) of the geopolymer spheres coated with $\mathrm{TiO}_{2}$ after (a) 2, (b) 4 and (c) 6 hours dwelling time (pink $=\mathrm{Ti}$, yellow $=\mathrm{Si}$ and $\mathrm{Al}$ or Geopolymer surface)

Elemental composition of the $\mathrm{TiO}_{2}-$ deposited geopolymer sphere was done via EDX analysis (Fig. 6). It can be observed that the three most distinct peaks are that of oxygen (56.70\%), silicon (15.73\%), aluminum $(14.55 \%)$ and titanium $(7.60 \%)$. The presence of silicon, aluminum and oxygen is due to the fact that the geopolymer sphere is composed of alumino-silicate network. This means that the nanomaterial has a titanium composition that verifies that it is, indeed, from the initial source powder which is $\mathrm{TiO}_{2}$. This was further confirmed by $\mathrm{Ti}$ elemental mapping, as shown in Figure 5 (left), where the pink-colored SEM image indicates Ti surface on the geopolymer.

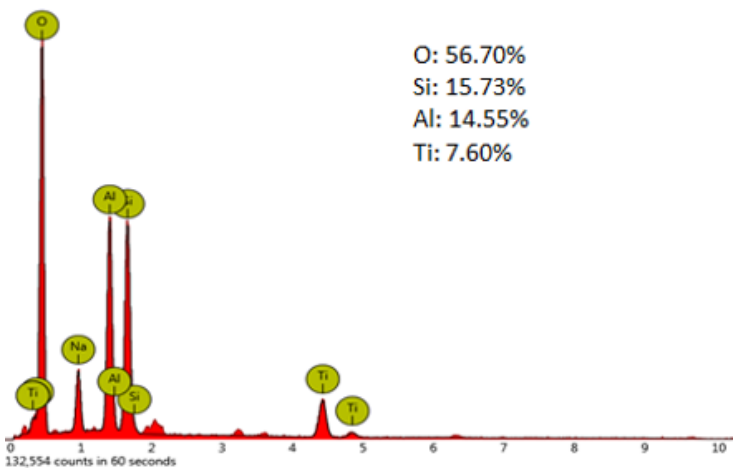

Figure 6. EDX analysis result for the six - hour dwelling time

\subsection{Photoactivity evaluation}

The photocatalytic activity of the synthesized $\mathrm{TiO}_{2}$-coated geopolymer spheres was determined and compared to bare geopolymer spheres, in terms of methylene blue degradation. Results reveal that after 10 hours, approximately $90 \%$ degradation was observed, while the uncoated geopolymer sphere gave $4.5 \%$ degradation. This suggests that incorporation of $\mathrm{TiO}_{2}$ on the geopolymer surface enhanced its photocatalytic activity. 
4 Conclusion

The main idea of this study is to produce a product of high value from low value materials such as waste, bearing also in mind of providing a utilization strategy of wastes that are largely produced in the Philippines namely, rice hull ash. In this study, it was showed that a cement material, known as geopolymers, can be produced from rice hull ash and metakaolin. This cement material's ability to break down pollutants was enhanced by coating it with titania in the form of nanocrystals through HVPG. Through the photocatalytic evaluation by the degradation of methylene blue (MB), results suggested that incorporation of $\mathrm{TiO}_{2}$ allowed degradation of methylene blue by $90 \%$ suggesting that (1) The geopolymer sphere was able to have an enhanced photocatalytic ability upon coating with $\mathrm{TiO}_{2}$ nanocrystals; (2) HVPG is a suitable $\mathrm{TiO}_{2}$ coating method for the geopolymer sphere. This study's potential environmental application in the treatment of wastewater will be investigated for future research.

The authors would like to acknowledge University Research Coordination Office - De La Salle University and Philippine Council for Industry, Energy and Emerging Technology Research and Development for financially supporting this research under PCIEERD Project No. 07132.

\section{References}

[1] World Rice Statistics Online Query Facility. Available online: http://ricestat.irri.org:8080/wrsv3/entrypoint. htm (accessed on 18 July 2018).

[2] Kalaw, M., Culaba, A., Hinode, H., Kurniawan, W., Gallardo, S., \& Promentilla, M. (2016). Optimizing and Characterizing Geopolymers from Ternary Blend of Philippine Coal Fly Ash, Coal Bottom Ash and Rice Hull Ash. Materials,9(7), 580. doi:10.3390/ma9070580

[3] Khan, Rawid \& Jabbar, Abdul \& Ahmad, Irshad \& Khan, Wajid \& Khan, Akhtar \& Mirza, Jahangir. (2012). Reduction in environmental problems using rice-husk ash in concrete. Construction and Building Materials. 30. 360365. 10.1016/j.conbuildmat.2011.11.028.

[4] Gibbs, M. J., Soyka, P., \& Conneely, D. (n.d.). $\mathrm{CO} 2$ Emissions from cement production. Good Practice Guidance and Uncertainty Management in National Greenhouse Gas Inventories. Retrieved August 16, 2018, from https://www.ipccnggip.iges.or.jp/public/gp/bgp/ 3_1_Cement_Production.pdf.

[5] Swaminathen A.N., and S. R. Ravi (2016), "Use of Rice Husk Ash and Metakaolin as Pozzolonas for Concrete: A Review", International Journal of Applied Engineering Research, Vol. 11, Issue 1 (2016) pp 656-664.

[6] Barbosa, V. F., \& Mackenzie, K. J. (2003). Synthesis and thermal behaviour of potassium sialate geopolymers. Materials Letters,57(9-10),
1477-1482. doi:10.1016/s0167-577x(02)010091

[7] Khan, R., Jabbar, A., Ahmad, I., Khan, W., Khan, A. N., \& Mirza, J. (2012). Reduction in environmental problems using rice-husk ash in concrete. Construction and Building Materials,30, 360-365. doi:10.1016/j.conbuildmat.2011.11.028

[8] ., B., \& M.c., P. (2012). Effect of Replacement of Cement by Metakalion on the Properties of High Performance Concrete Subjected to Acid Attack. I-managers Journal on Civil Engineering,2(3), 14-21. doi:10.26634/jce.2.3.1934

[9] Bakharev, T. (2005). Resistance of geopolymer materials to acid attack. Cement and Concrete Research,35(4), 658-670. doi:10.1016/j.cemconres.2004.06.005

[10] Barbosa, V. F., \& Mackenzie, K. J. (2003). Thermal behaviour of inorganic geopolymers and composites derived from sodium polysialate. Materials Research Bulletin,38(2), 319-331. doi:10.1016/s0025-5408(02)01022-X

[11] Ole, A., Abrasaldo, P. M. B., Castillon, G., Ladines, A., de los Reyes, R., Santos, G. N. C., \& Quiroga, R. V. Synthesis of $\mathrm{TiO} 2$ Nanomaterials by Modified Horizontal Vapor Phase Growth Technique.

[12]Zailan, S. N., Mahmed, N., Abdullah, M. M., \& Sandu, A. V. (2016). Self-cleaning geopolymer concrete - A review. IOP Conference Series: Materials Science and Engineering, 133, 012026. doi:10.1088/1757-899x/133/1/012026

[13] Ohtani, B., Kakimoto, M., Nishimoto, S., \& Kagiya, T. (1993). Photocatalytic reaction of neat alcohols by metal-loaded titanium(IV) oxide particles. Journal of Photochemistry and Photobiology A: Chemistry,70(3), 265-272. doi:10.1016/1010-6030(93)85052-a

[14] Quagliarini, E., Bondioli, F., Goffredo, G. B., Cordoni, C., \& Munafò, P. (2012). Self-cleaning and de-polluting stone surfaces: $\mathrm{TiO} 2$ nanoparticles for limestone. Construction and Building Materials, 37, 51-57. 